tion in cases of obesity or difficulty with the bowel, since the high fibre content reduces the calorie value but increases the aperient properties. - I am, etc.,

T. L. Cleave

Fareham, Hants

1 Morris, J. N., Lancet, 1941, 1, 51.

Connell, A. M., Hilton, C., Irvine, G., Lennard Jones, J. E., and Misiewicz, J. J., British Medical fournal, 1965, 2, 1095

Moran, T., Bread. London, Constable, 1954

Lournal of the Royal Naval Medical Cleave, T. L., and Campbell, G. D., Diabetes, coronary thrombosis and the saccharine disease, Bristol, Wright, 1966.

\section{Varieties of Memory}

SIR,-As an amateur pianist, I was very interested in the last paragraph of "Personal View" by Professor L. J. Witts (1 April, p. 43) and can perhaps throw a little light on the subject of how performers memorize music. He draws attention to visual and auditory memory. I believe that there is a third type, which might be described as kinaesthetic, which stems from the muscles, joints, and nerves of the upper limb.

When learning the piano 50 years ago I soon found that after practising a piece of music I could close the book and play it from memory having made no conscious effort to memorize it; visual memory played no part at all in this and auditory memory a minor one, but my fingers seemed to know where to go next. This facility persists, for I still find that I can play a piece of music from memory which I have not played for perhaps 20 years or more.

I am sure that the degree to which these various forms of memorizing are used varies with the individual performer and their relative importance varies, but I also think that without kinaesthetic memory-even well developed visual memory-it would not be possible for a concert pianist, say, to command his large repertoire of memory performances.-I am, etc.,

T. D. Culbert

Manchester

\section{New Thoughts on Essential Hypertension}

SIR,-Your leading article "New Thoughts on Essential Hypertension" (15 April, p. 121) argues against the prolonged use of diuretics in mild hypertension and therefore must interest the obstetrician in his treatment of pre-eclampsia, wherein they have been employed. You have indicated that low levels of sodium thereby brought about could act as a stimulus for renin release and defeat the desired hypotensive effect.

In this connexion the risk of provoking hyponatraemia in pregnancy has long been recognized, while recently Chesley ${ }^{1}$ has warned against their use, but for a different reason. He has brought evidence to show that as "toxaemia" mounts hypovolaemia and haemoconcentration also increase and these two states are exacerbated by the resultant plasma depletion.

Leyssac $^{2}$ maintains that changes in glomerular filtration rate are secondary to alterations in the reabsorptive rate of the proximal tubule. Thus the increased loss of fluid by the tubule would effect a corresponding increase in glomerular filtration, in turn producing a reduction in the tone of the glomerular afferent arteriole and implying a reduction in its stimulation by renin
Therein may lie its hypotensive action.

Though it is difficult to account for the effects of specific changes in glomerular pressure per se on reabsorption, such a mechanism could well underlie the usefulness of diuretics in pre-eclampsia.-I am, etc.

JOHN SOPHIAN

Worthing, Sussex

1 Chesley, L. C., American Fournal of Obstetrics

ly63, 88, P., Acta Physiologica Scandinavica

\section{Sabbatical Year}

SIR,-While I agree to a large extent with Dr. R. E. Loder (22 April, p. 226) and many consultants in the National Health Service both deserve and need a real break from routine duties at long intervals, I think that this applies particularly to those working maximum part-time or whole-time clinical appointments outside teaching hospitals. While consultants in teaching hospitals are not immune to pressures or to stress the scale of assistance is usually much higher than for their contemporaries in nonteaching hospitals, upon whom heavy routine work falls far more directly.

If Dr. Loder's suggestion were acted upon I believe that many early retirements would be prevented and that the standard of consultant working in those whose burden has been exceptionally heavy would be preserved to a degree which is at present seldom achieved.-I am, etc.

Tyrone County Hospital

T. J. WILMOT Omagh, Co. Tyrone

\section{Family Doctors and Contraception}

SIR,-The vice-president of the Pharmaceutical Society, Mr. J. P. Kerr, speaking in Glasgow on Sunday, 26 March at a conference sponsored by the Socialist Medical Association, pressed the Society's view that oral contraceptives should be available on the National Health Service. Mr. Kerr outlined the Society's proposed scheme, in which family doctors would issue prescriptions on a modified E.C.10 form. This special form would be similar to the E.C. 19 form and would contain a total of three separate prescriptions. At each consultation the doctor would issue prescriptions for three or six months' supply (see the Pharmaceutical Fournal, 8 April 1972, p. 312).

Dr. Lorna Naismith, speaking on behalf of the Family Planning Association, agreed that contraceptive services should be completely free. However, she felt that contraceptives should be supplied only by those who had received special training. Asked to comment on the Pharmaceutical Society's plan, Dr. Maurice Miller (who takes a weekly birth control session at a London Family Planning Association clinic) replied that he also had reservations that the training of many general practitioners in this specialized field was not deep enough. Early detection of untoward side effects, for which the family doctor had neither the time nor the experience, was best carried out at family planning clinics, he added.-We are, etc.

B. L. Furman A. L. HaRvey Department of Pharmacology, University of Strathclyde, Glasgow

\section{Fair Wage for Auxiliaries}

SIR,-Dr. B. E. Brocks (18 March, p. 753) is to be congratulated on the firm stand he has taken on behalf of the remedial professions, particularly in respect of their system of grading and appallingly low salaries. His words come as a timely warning in a situation which is rapidly worsening.

$\mathrm{He}$ does them a disservice, however, by referring to them as medical auxiliaries, when in fact they are recognized by Act of Parliament, with other groups, as the "professions supplementary to medicine." Without wishing to be accused of pedantry, I am sure Dr. Brock will appreciate the subtlety of the difference between the dictionary definitions of "auxiliary" and "supplementary." It adds a measure of gloss to the skills and enthusiasm of the supplementary professions.-I am, etc.,

R. BROOKS

Public Health Laboratory,

Swansea

\section{Future of Mental Health Services}

SIR,-We read with interest the wellintentioned letter by Drs. F. A. Bleaden and J. H. Price (4 March, p. 624). As they are so critical of psychiatric units in general hospitals and the policy of the Manchester region, some clarification is necessary. We are not qualified to express any comments on the future of services for mentally subnormal patients, but we have sufficient experience of general hospital psychiatry to make the following comments. ${ }^{1}$

For most of us who studied carefully the findings of the Whittingham Hospital Inquiry, ${ }^{2}$ it must be fairly obvious that the sorry state of affairs at that hospital was more due to other failings than to lack of funds. Finance, however, inadequate as it has been for most of us in the N.H.S., should not be the decisive factor in formulating future policy. One of us has already criticized the mistaken policy of a premature run-down on mental hospital beds until adequate facilities are developed in the community and better care provided for the increasing number of elderly confused patients. $^{3}$

We agree that a greater flexibility in planning is needed than that displayed in the White Paper recently published by the Department." Local conditions and existing facilities must be taken into account. We disagree entirely with Drs. Bleaden and Price that acutely disturbed psychotic patients cannot be treated as adequately (not "housed") in an active therapeutic community of a general hospital, with its modern clinical facilities, as in a sometimes remote mental hospital. Similarly, personality disorders are better managed in a day hospital nearer home or in the outpatient clinic. Many of those with them should not be hospitalized at all. Many fail to respond, wherever they are.

We think that in the foreseeable future there will still be a real need for active, progressive. mental hospitals with their own areas of clinical responsibility and greater involvement with community services. Some may develop regional special units for forensic psychiatry, drug addiction, and rehabilitation for long-stay patients. They will become smaller and easier to manage when 